\section{O diário de campo na experiência inicial docente}

\author{
The field journal in the initial \\ teacher's experience
}

Sheila Oliveira LIMA (UEL) sheilaoll@uol.com.br

Recebido em: 29 de maio de 2018. Aceito em: 28 de set. de 2018.
LIMA, Sheila Oliveira. O diário de campo na experiência inicial docente. Entrepalavras, Fortaleza, v. 8, n. 3, p. 126-141, out-dez/2018.

Resumo: O estágio é a primeira experiência de ensino para os alunos do curso de Licenciatura em Letras Português. Nos anos de 2016 e 2017, os alunos do terceiro ano registraram sua experiência de estágio em diários de campo. Embora seja considerada uma inovação nas experiências de estágio, o diário de campo é difundido em pesquisas geográficas e antropológicas. O objetivo do uso de diários de campo foi fazer com que os alunos observassem e registrassem o ambiente de estágio, a fim de trazêlos para uma profunda reflexão sobre a experiência ali vivenciada. Durante tal período, os estudantes registraram suas experiências nos diários e, ao final término, cada aluno escreveu um artigo reflexivo baseado em seu diário de campo. As análises dos artigos concluíram que o diário de campo aprimora a experiência de estágio, levando o estudante a uma formação docente autêntica.

Palavras-chave: Diário de campo. Estágio. Formação docente. 
Abstract: The internship is the first teaching experience to the students of the Portuguese Language and Literature Major. In 2016 and 2017, third-year students registered their internship experience in field journals. Although it is considered some of an innovation in the internship experiences, field journal is widespread in geographical and anthropological researches. The objective of using field journals was to make students observe and register the internship environment, in order to bring them to a deep reflection on the internship experience. During the internship, the students registered their experiences in field journals. At the end of the internship, each student wrote a reflexive article based on their field journal. My analyses of the articles concluded that the field journal enhances the internship experience, bringing the student to an authentical teaching formation.

Keewords: Field journal. Internship. Teacher formation.

\section{Introdução}

O estágio supervisionado tem se caracterizado, cada vez mais, como uma atividade fundamental para a formação inicial docente, na medida em que, de saída, configura-se como atividade capaz de fomentar a reflexão a respeito da tensão existente entre os dois aspectos essenciais do trabalho pedagógico: o conhecimento teórico e a sua transposição para o campo da ação educacional. Ao lado dessa tensão, outro fator se coloca de modo cada vez mais pungente na pauta das discussões oriundas desse processo: o lugar atual da docência, fortemente afetado pela desvalorização da profissão docente.

Muitos estudantes, quando iniciam as disciplinas da área de Metodologia do Ensino ou quando se veem na iminência de vivenciar a experiência docente, seja no estágio supervisionado ou em programas como o PIBID (Programa Institucional de Bolsa de Iniciação à Docência), expressam preocupações bastante sintomáticas, considerando o atual status da docência em nosso país. Vários estagiários e pibidianos, em seus relatórios finais e nos processos de orientação, evidenciaram o receio que têm de serem desrespeitados pelos seus alunos. Apesar desse temor, almejam a constituição de uma postura ética, pautada pelo diálogo e pelo respeito mútuo. Na esteira dessa segunda preocupação, esboçam-se outras, sendo a principal delas a busca por estratégias adequadas ao ensino da língua portuguesa, baseadas em uma concepção de linguagem enquanto interação.

Observa-se, a partir dessas demandas, que o processo de formação docente não se limita a uma construção meramente técnica, resultante do conhecimento e aplicação de métodos e estratégias. Tal percurso implica a constituição de identidades, o que requer disposição do aluno para vivenciar processos de transformação de si e do seu 
v. 8 (3)

$126-141$

out-dez

2018

olhar a respeito do ensino e do seu lugar enquanto professor. Por outro lado, demanda uma atenção constante do supervisor de estágio, no sentido de amparar esse processo, conduzindo-o a uma experiência verdadeiramente formativa.

A partir desse quadro de preocupações, surgiu o trabalho de supervisão de estágio apoiado na ferramenta diário de campo (doravante DC). Frequente nas pesquisas da área de ciências da natureza e na antropologia, o DC mostrou-se um instrumento bastante eficaz na ampliação do diálogo entre supervisor e estagiário, além de potencializar as reflexões deste último a respeito do seu imaginário relativo ao ensino, à profissão docente, às estruturas da educação no país.

Neste artigo, procura-se apresentar uma proposta de estágio pautada pela discussão sobre o lugar da docência e o lugar do estagiário - futuro docente - nesse contexto, a partir dos registros de suas observações e sentimentos vividos na sua experiência inicial. Para tanto, iniciamos com uma discussão teórica que procura articular os conceitos de metodologias ativas, identidade docente e a concepção de professor-pesquisador. Em seguida, apresenta-se a ferramenta DC e suas possibilidades de contribuição no processo reflexivo do docente em formação. Por fim, são analisados excertos de dois artigos de estudantes, nos quais se registram elementos essenciais do processo de estágio, resultantes das discussões motivadas pelos registros nos DC.

\section{O diário de campo na pauta das metodologias ativas para a formação de um professor-pesquisador}

A formação do profissional docente, em consonância com o caráter da própria profissão, requer uma articulação bastante consistente entre os aspectos teóricos e os práticos, na medida em que essas duas instâncias formativas e de realização do trabalho se alimentam mutuamente para a efetivação das práticas de ensino.

No tocante às abordagens que amparam a supervisão das atividades de estágio, as metodologias ativas parecem inerentes a todo processo desse teor, visto que se trata de uma disciplina de ordem prática. Entretanto, é comum que a ação do supervisor de estágio se limite a uma orientação cuja reflexão ou atividades de ordem teórica estejam fixadas na leitura e compreensão de textos já consagrados, os quais trazem formulações acabadas. 
Uma metodologia ativa perverte esse caminho. Isto é, dimensiona a aprendizagem a partir do enfrentamento da realidade e das dificuldades e soluções bem sucedidas advindas desse processo. Então, a partir da experiência, sistematiza o conhecimento em linguagem teórica e em método. Jacques Rancière, em "O sábio ignorante", relata a experiência de um professor que criou seu método de ensino a partir de uma situação absolutamente inusitada para si: deveria ensinar francês a estudantes holandeses sem conhecer o idioma local. A partir desse inusitado e bem sucedido acontecimento, Rancière (2013, p. 35) conclui que "Não há homem na Terra que não tenha aprendido alguma coisa por si mesmo e sem mestre explicador."

No caso do estágio curricular, entretanto, o supervisor não se ausenta da experiência. Mas, na categoria de "mestre", pode se colocar menos enquanto "explicador" e mais enquanto "debatedor" ou "problematizador" da experiência vivida por seus estagiários, ajudandoos a refletir sobre o vivido e mediando o acesso a pensadores e teóricos cujas formulações possam contribuir com tal discussão. Nessa direção, adere às metodologias ativas que, segundo Berbel (2011, p.29)

baseiam-se em formas de desenvolver o processo de aprender, utilizando experiências reais ou simuladas, visando às condições de solucionar, com sucesso, desafios advindos das atividades essenciais da prática social, em diferentes contextos.

A partir desse pressuposto, é possível conceber um trabalho de supervisão de estágio voltado para uma experiência que não se esgote no fazer - nas observações e regências - contraposto a certas teorizações, mas que conduza para a construção de uma postura docente alicerçada no constante ato reflexivo, o que introduz também uma conduta baseada na auto-avaliação e na auto-formação, vale dizer, na autonomia.

Nessa perspectiva formativa, é possível entrever um canal para a constituição de um perfil docente aliado ao do professor-pesquisador que, segundo Fagundes (2016, p. 295), pode ser conceituado a partir das seguintes proposições:

Estejam implicados professores e pesquisadores que (...) buscam compreender a natureza dos fenômenos educativos em razão da necessidade de aprendizado dos alunos e de sua formação humana;

[...]

A reflexão seja concebida como um processo humano que se dá, individual e coletivamente, em busca de entendimento a respeito dos diferentes aspectos sociais, psicológicos, afetivos, políticos e educacionais. 
v. $8(3)$

$126-141$

out-dez

2018

Tal perfil docente, fundamentado no olhar investigativo em relação aos processos de ensino-aprendizagem, coaduna-se fortemente com a perspectiva das metodologias ativas, na medida em que ambos se constituem a partir da reflexão individual e coletiva sobre as práticas e os resultados da docência.

Entretanto, o imaginário relativo à docência, ao lugar do professor na sala de aula, ainda é marcado pelo distanciamento dos alunos e pela postura pouco reflexiva em relação aos resultados e aos caminhos da prática docente. Sendo assim, uma metodologia ativa que leva à formação de um professor com perfil de pesquisador, aberto a uma constante aprendizagem e disposto à alteração dos métodos, dos materiais e mesmo dos objetivos a serem alcançados, toca fortemente em questões identitárias.

Torna-se, portanto, fundamental observar as implicações dessas metodologias na constituição dos traços relativos à identidade docente, na medida em que a proposição de uma prática baseada na pesquisa e na reflexão, em certa medida, contrapõe um perfil cristalizado e ainda em franca atividade na escola brasileira.

Conforme mencionado na introdução deste artigo, uma das maiores preocupações dos estagiários é não reproduzir posturas autoritárias ou pouco respeitosas em relação aos alunos, condutas que expressam claramente a ausência de reflexão e de autocrítica. Nesse sentido, observase já nas demandas dos docentes em formação inicial uma busca pela construção de uma identidade que diverge do que conhecem tão bem, porém do ponto de vista de estudantes que foram até então.

O processo de construção identitária, no caso da formação docente, implica diversos aspectos. Talvez o mais significativo deles seja justamente a cultura que se tem constituído em torno de tal atividade.

A construção da identidade do educador passou, ao longo dos séculos, por transformações significativas, o que, entretanto, não alterou de maneira expressiva o imaginário que circunda a atuação desse profissional nos contextos mais amplos.

Ao retomar a história da educação, desde a Grécia Antiga até os dias atuais, Geraldi (2003) assinala três identidades distintas. A primeira delas, localizada entre os gregos antigos, refere-se ao professor enquanto produtor do conhecimento, o mestre que conduz seus discípulos a uma reflexão que ele considera pertinente. A segunda identidade nasce na época do Mercantilismo, quando o conhecimento passa a ser também um produto a ser comercializado. O professor, nesse momento, assume o lugar de transmissor de um conhecimento 
produzido por outrem e cujo valor é dado pela sua necessidade em dar prosseguimento às relações comerciais e de produção. Por fim, atualmente, o lugar do professor parece tornar-se ainda mais lateral, mais distante da produção do conhecimento, ocorrendo o que Geraldi qualifica como "exercício da capatazia (2003, p. 95). Isto é, quando os materiais didáticos passam a determinar a prática do professor, deslocando-o de uma atuação autônoma e autêntica, na medida em que deve obedecer a um plano criado por outros e que não corrobora minimamente com os contextos reais de atuação.

Diante dessa realidade, torna-se cada vez mais indispensável conduzir a formação docente a partir de práticas que recoloquem o professor num lugar de autonomia e de consciência em relação ao seu fazer. Conforme sinalizam os estudantes no relato de suas primeiras angústias em relação a suas posturas em sala de aula, talvez uma importante saída seja a construção de uma identidade pela assunção da diferença. Segundo Silva (2012, p. 76),

A identidade e a diferença têm que ser ativamente produzidas. Elas não são criaturas do mundo natural ou de um mundo transcendental, mas do mundo cultural e social. Somos nós que a fabricamos, no contexto de relações culturais e sociais. A identidade e a diferença são criações sociais e culturais.

E a diferença, no atual quadro da educação, certamente passa pelo reposicionamento do professor, assumindo seu lugar de reflexão e de ponderação da sua prática.

Nesse sentido, no redirecionamento de uma construção identitária pautada pela reflexão, conforme se observa na concepção de professor-pesquisador e na condução dos processos formativos proposta pelas metodologias ativas, é possível articular a formação inicial docente de modo a estruturar posturas de autonomia e responsabilidade ética. Nessa tessitura, é viável alinhavar o DC enquanto ferramenta que organiza e arremata o processo reflexivo do período de estágio supervisionado.

O DC configura-se como um modo de registro oriundo da pesquisa em antropologia, sendo também bastante comum em registros realizados pela área de geografia. Nele, o pesquisador realiza todo tipo de anotação pertinente ao contexto explorado, sem preocupação com o modo de escritura, podendo ser em linguagem verbal, visual, colagens etc. O conteúdo das anotações também é bastante variado, podendo configurarse em inscrições de ordem mais objetiva ou mesmo elucubrações mais subjetivas. Segundo Bogdan;Bliken (1995, p.152 apud ROESE; GERHARDT; 
v. $8(3)$

$126-141$

out-dez

2018

SOUZA; LOPES, 2006, p.2), o diário de campo configura-se em dois modos de registro: o descritivo, "em que a preocupação é a de captar uma imagem por palavras do local, pessoas, ações e conversas observadas" e o reflexivo, isto é, "a parte que apreende mais o ponto de vista do observador, as suas idéias e preocupações". Entretanto, conforme bem alertam ROESE; GERHARDT; SOUZA; LOPES (2006), num instrumento como o diário, há sempre o risco de um excesso de subjetivismo. Os autores ainda comentam a possibilidade de demarcação dos dados subjetivos como CO (Comentários do Observador) ou mesmo da escrita de dois diários distintos, sendo um mais objetivo e outro mais subjetivo. Entretanto, defendem que o DC tende a ser mais produtivo, desde que integre "descrição e reflexão, mostrando uma seqüência temporal dos acontecimentos, tanto da realidade investigada, quanto do tempo dos investigadores, e sua imersão no processo investigativo.» (ROESE; GERHARDT; SOUZA; LOPES: 2006, p. 2)

Dentro de uma perspectiva formativa, entende-se que a opção por um único diário, conforme sugerido pelos autores, mostra-se mais eficaz, na medida em que possibilita o surgimento de questões de toda ordem - técnicas ou afetivas - que deverão ser abordadas nos momentos de reflexão apoiados pelo supervisor de estágio. Por outro lado, o DC nesse teor aponta para uma postura de constante reflexão sobre o acontecimento da sala de aula e de auto-avaliação da performance de ensino. Nesse sentido, articula um hábito constituído a partir do olhar atento e investigativo sobre o próprio fazer e sobre seus efeitos no processo de ensino-aprendizagem. Trata-se, portanto, de uma ferramenta que se expande para além do momento de sua execução enquanto instrumento de registro, passando a valer como metodologia de trabalho docente, com a perspectiva de uma formação contínua, baseada na ressignificação da prática a partir da constante reflexão teórica sobre a atividade em curso.

Vale ressaltar que a proposta do trabalho com o DC pretende extrapolar a função de registro para uma reflexão imediata sobre a prática ou como metodologia para a formação de um docente identificado com uma postura de professor-pesquisador. Almeja-se, ainda, que o DC se torne uma memória do período em que o aluno passou pela experiência do estágio, podendo ser revisto, retomado e ressignificado ao término do percurso por meio de uma reflexão apoiada teoricamente (como é o caso do artigo produzido). Entretanto, tal qual um diário de cunho pessoal, o instrumento pode ainda ressurgir, mais adiante, ao licenciado, já em pleno exercício da docência, como um referencial para o reposicionamento da prática docente. 


\section{O contexto do estágio supervisionado em Letras na UEL}

O estágio supervisionado em Letras - Português é uma disciplina obrigatória do curso de Licenciatura em Letras da Universidade Estadual de Londrina. Apesar das alterações curriculares ocorridas ao longo dos últimos anos e em consonância com as orientações oficiais, a disciplina mantém como princípio as atividades de observação, pesquisa e docência nas escolas como eixo fundamental dos conteúdos desenvolvidos.

Realizado nos dois últimos anos do curso, o estágio supervisionado soma 400 horas, sendo 180 referentes ao $3^{\circ}$ ano e 220 ao $4^{\circ}$ ano, devendo ser efetuada 30\% dessa carga em atividades práticas, no espaço escolar, como: pesquisa, regência, observação, participação junto ao professor, avaliação de trabalhos etc.

A execução do estágio configura-se, portanto, pela vivência na escola, supervisionada pelo docente da universidade e com a colaboração do professor da escola concedente. De um modo geral, o período de estágio culmina com as regências do estudante e a apresentação de relatório final com a descrição das atividades realizadas. Ao longo de todo o processo, os professores-supervisores acrescentam outras atividades como forma de amparar as reflexões dos alunos, auxiliar na produção dos planos de aula e, por fim, nos registros de conclusão da disciplina. Essas atividades, frequentemente, se realizam por meio de leituras de textos teóricos e reuniões de orientação.

Apesar de as atividades, como as propostas acima, surtirem bons resultados práticos no tocante às regências, foi observado que os relatórios finais dos alunos que as realizavam eram, em geral, pouco ou nada reflexivos. Limitavam-se a um inventário das atividades efetuadas e das pesquisas registradas, sem haver qualquer menção às possíveis inquietações que a experiência pudesse ter causado. Dessa constatação surgiu o questionamento a respeito do quanto a atividade docente no período de estágio estaria, de fato, se estabelecendo enquanto uma metodologia ativa, no sentido de revolver sentidos, de por em funcionamento reflexões oriundas de desafios, dificuldades e até surpresas que o campo de estágio poderia instaurar, na medida em que se trata de um contexto sempre vivo, de interações em franca atividade. Questionou-se, portanto, o quanto as metodologias de então estavam sendo eficazes para a formação de um professor aberto à percepção de si e de sua ação, capaz de reorientar seu trabalho conforme a observação dos resultados, num processo de constante auto-formação. 
v. 8 (3)

$126-141$

out-dez

2018

Nos anos de 2016 e 2017, buscando evitar o risco de uma passagem pouco ou nada significativa pelo campo de estágio, em algumas turmas de $3^{\circ}$ ano, optou-se pela alteração na abordagem metodológica, instaurando-se o DC como ferramenta fundamental nesse processo de formação docente.

Os alunos desses grupos foram, então, orientados a realizar registros não apenas a respeito da prática do professor regente, mas de todo o contexto escolar observado. Também foi solicitado o registro das impressões a respeito do desempenho do licenciando e do contexto de sala de aula nos dias de suas regências. Notas de situações que extrapolam a sala de aula também foram indicadas como concernentes ao DC.

Após o período de estágio, o DC foi entregue ao professor supervisor, que o leu e, em seguida, retomou seu conteúdo com o licenciando numa sessão de orientação em que foram destacados tópicos que se mostraram relevantes ao longo dos registros, seja pelo insistente comparecimento ao longo das anotações, seja pela relevância da temática. A partir do debate entre estagiário e supervisor sobre os registros realizados, foram elencados temas a serem abordados em um artigo acadêmico, o qual deveria refletir sobre tais assuntos com apoio das teorias tratadas nas aulas da disciplina de Metodologia.

\section{Do diário ao artigo: enlaces}

Como forma de observar a eficácia imediata do uso da ferramenta DC na construção de uma reflexão a respeito da prática, com vistas a uma elaboração mais sólida da atividade docente, foram acompanhados 9 estudantes, sendo 5 em 2016 e 4 em 2017, todos do $3^{\circ}$ ano do curso de licenciatura em Letras - Português.

O trabalho de acompanhamento dos estudantes operouse pela orientação das atividades iniciais de estágio, como pesquisa sobre a escola, observação do campo (tanto sala de aula como das demais ambiências da escola), atividades de planejamento e avaliação junto ao professor regente, entre outras. Tais orientações bem como a supervisão das regências apoiaram-se nas discussões teóricometodológicas oriundas das atividades desenvolvidas na disciplina de Metodologia do Ensino de Língua Portuguesa e de Literaturas de Língua Portuguesa, também constante do currículo de curso dos anos em análise. 
Nessas primeiras instruções, foi apresentada a ferramenta DC, explicitando o seu caráter de registro de observação, sensações, dúvidas, inquietações surgidas durante todo o processo de estágio. Nesse momento também foi informado que o registro seria utilizado como fonte de dados para a escrita de um artigo reflexivo a respeito da experiência inicial docente.

Ao longo do período de realização do estágio, foram realizadas reuniões coletivas e individuais como forma de debater algumas das questões mais pungentes que surgiram ao longo das atividades, bem como com a finalidade de esclarecer dúvidas a respeito da construção dos planos de aula e das estratégias desenhadas pelos alunos para a abordagem dos conteúdos programáticos determinados em reunião com o professor regente da escola.

Ao final do processo, os alunos entregaram seus diários de campo, os quais foram lidos e, neles, elencados temas para o desenvolvimento de reflexões mais aprofundadas e amparadas teoricamente. As reuniões para tratar das possíveis discussões a partir dos dados presentes nos diários foram realizadas individualmente, num processo dialógico, buscando-se, assim, que o aluno encontrasse, em suas inquietações, motivos e proposições que viessem enriquecer sua identidade docente ainda em construção.

\section{Das angústias diárias às reflexões articuladas: análise de excertos dos artigos}

Como forma de sistematizar as reflexões apontadas nos diários de campo, conforme dito antes, foi solicitado aos alunos participantes do processo aqui descrito que produzissem um artigo acadêmico, traçando uma reflexão a partir de temas presentes no DC. Para tanto, a professora supervisora, ao analisar o diário de cada aluno, elencou possíveis temas e os debateu com os estudantes, sugerindo possíveis conexões com textos lidos na disciplina de Metodologia e nas reuniões coletivas das orientações de estágio.

Sendo assim, o grupo do ano de 2016 produziu quatro artigos, sendo três de autoria individual e um em coautoria. No ano de 2017, foram escritos quatro artigos individualmente.

As normas para a estruturação dos artigos seguiam orientações dadas por eventos tradicionais da universidade, dos quais os alunos estavam habituados a participar, como o Seminário de Pesquisa em Ciências Humanas e o Selisigno ${ }^{1}$.

${ }^{1}$ O primeiro evento ocorre a cada dois anos e reúne pesquisas de alunos e professores de todos os cursos do Centro de Letras e Ciências Humanas da UEL. O segundo, também bianual, refere-se a pesquisas das áreas de Linguística e Literatura. 
v. $8(3)$

$126-141$ out-dez 2018

Optou-se por analisar apenas os artigos resultantes da experiência de registro com o DC em lugar do próprio diário por dois motivos principais. O primeiro deles refere-se à necessidade de preservação da identidade dos estagiários. Entende-se que os enunciados presentes nos DC, por se darem de modo mais livre, poderiam levar a interpretações em que, ausente o contexto, ocorressem mal-entendidos de diversa ordem, expondo desnecessariamente seus autores. A segunda motivação para a fixação da análise nos artigos refere-se ao fato de, neles, a reflexão oriunda das vivências registradas nos DC encontrar-se mais madura e melhor sistematizada, permitindo, assim, interpretações mais eficazes do processo de construção da identidade docente.

Serão aqui analisados excertos de dois artigos produzidos nos períodos de 2016-2017, os quais foram apresentados no evento $1^{0}$ Estagiar, realizado pela área de Metodologia do Ensino do curso de Letras - Português, no ano de $2017^{2}$, e publicados em anais eletrônicos. O artigo 1, de autoria de Patrícia Medeiros Galvão e Natália Cristina Sá, resulta das atividades de estágio do ano de 2016. O texto 2, de autoria de Aline Fracarolli do Carmo, constitui a síntese das reflexões sobre estágio realizado em 2017. Ambos os trabalhos, para serem apresentados no Estagiar, foram avaliados por uma comissão de professores da área de Metodologia, sendo que nenhum dos seus membros foi supervisor de estágio das autoras, garantindo-se, assim, a isenção na seleção bem como a qualidade dos textos das propostas de comunicações a fazerem parte do evento.

Em todos os artigos produzidos nos anos de 2016-2017, mesmo aqueles quenão fazem parte das análises aqui apresentadas, foram observados processos reflexivos bastante maduros em relação à formação docente. Destacam-se três principais: a permanente auto-avaliação das atividades desenvolvidas no estágio, a reflexão sobre o contexto escolar enquanto espaço complexo de interação e produção de sentidos e a compreensão do desafio de ensinar língua portuguesa a crianças e adolescentes.

A primeira perspectiva dilui-se entre as demais abordagens. Isto é, observa-se em todos os artigos uma clara tendência a olhar para o próprio trabalho de modo crítico, buscando uma compreensão do processo que inclua a avaliação da atuação do estagiário.

\footnotetext{
${ }^{2} \mathrm{O}$ evento Estagiar é um encontro promovido pela área de Metodologia do Ensino do Curso de Licenciatura em Letras - Português da Universidade Estadual de Londrina com o objetivo de compartilhar as experiências de estágio supervisionado entre os diversos atores que dela participam, congregando escola e universidade para o debate a respeito da formação inicial docente. O Estagiar publica anais em ebook com registros de todas as apresentações realizadas no evento.
} 
Iniciamos as análises pela apreciação do artigo 1, produzido em co-autoria por estudantes do ano de 2016. No texto, ao relatar a tentativa de realização de uma atividade oral cujo objetivo era o compartilhamento das interpretações das leituras feitas pelos alunos, expõe-se a seguinte situação:

Em sala de aula, experiências e vivências estão reunidas num
mesmo espaço, esperando o momento de serem exploradas.
Para tanto, a escola deve encontrar uma forma de ensinar,
incentivar e impulsionar a expressão da oralidade. É importante
registrar também o fato de que os alunos demonstraram
contentamento em produzir os textos orais e tiveram excelente
desenvoltura nesta atividade. Entretanto, pelo fato de estarem
tão condicionados a entender aula como apenas fazer cópias de
textos da lousa ou do livro didático, apresentaram uma grande
dificuldade em respeitar e fazer silêncio enquanto o colega
fala: todos acabaram falando ao mesmo tempo, o que acabou
transformando-se em uma grande gritaria. Isso revela que o
trabalho com a oralidade no que diz respeito à participação
interativa do aluno dando voz a seus pensamentos tem sido
tão escasso na escola que os alunos não conseguem ou não
aprenderam operar com o revezamento nos turnos de fala.
Quanto mais atividades orais realizamos, porém, melhor foi
o comportamento dos alunos no decorrer destas atividades:
quanto mais os alunos compreendiam que a oralidade também
faz parte do contexto ensino aprendizagem (e não apenas de
brincadeiras e descontração), mais respeitavam a tomada de
palavra dos colegas e levavam a sério seu próprio discurso,
desenvolvendo não só competência comunicativas orais, mas
também de respeito, diálogo e outras características necessárias
à convivência em sociedade. (GALVÂO; SÁ: 2017 , p.107. Grifos
nossos)

No excerto acima, de saída, observa-se uma postura autoavaliativa, na medida em que as autoras não se poupam na crítica que fazem à tentativa de realizar um trabalho oral com crianças que desconheciam atividades dessa ordem. Embora não mencionem a si de modo explícito, tratam o problema implicando-se nele, sobretudo quando evidenciam a situação caótica em que se transformou a sala de aula: "o que acabou transformando-se em uma gritaria". Ao lado disso, porém, ao reportarem que a situação se altera conforme persistem na proposição de atividades orais, revelam seu próprio percurso de aprendizagem, no entendimento de que toda competência a se construir exige um processo longo e frequente para seu pleno desenvolvimento.

Vê-se, portanto, que a conclusão a que chegam as estagiárias a respeito do desempenho final dos alunos passa por uma avaliação que expõe a pouca experiência inicial para lidar com o problema e o sucesso das soluções criadas durante o período de estágio. Essas 
v. $8(3)$

$126-141$

out-dez

2018

reflexões são fruto de um olhar amparado pelos registros do DC, sem o qual, talvez, não conseguissem recuperar a memória do caos inicial, visto que, em geral, tendemos a esquecer os eventos menos positivos e mais distanciados no tempo. A possibilidade de reportar-se ao passado e percorrer, nas anotações do DC, o histórico do movimento de apropriação dos alunos das práticas orais escolares em consonância com a frequência das propostas feitas pelas estagiárias, certamente, possibilitou um movimento reflexivo de ressignificação da prática.

Importante ressaltar, também, no trecho, que as considerações a respeito da atividade inicialmente mal sucedida encontram outros pontos nevrálgicos. O primeiro deles diz respeito ao próprio desafio de ensinar língua portuguesa, numa perspectiva mais complexa. Isto é, a crítica feita ao excesso de cópias e, portanto, de ausência de uma participação efetiva do aluno nos processos de interação em sala de aula é um dos aspectos que marca fortemente o excerto, seja pela crítica à supremacia do livro didático em relação a outros materiais, seja pela atitude passiva a que o aluno parece ser submetido, expressa no trecho pelo uso do adjetivo "condicionados". Reforça essa imagem o uso de "escassos" ao referir-se à ausente voz dos alunos e de seus pensamentos na sala de aula.

Nesse ponto da reflexão, entretanto, observa-se uma fusão de preocupações. Ao mesmo tempo em que se coloca a premente necessidade do trabalho com a oralidade, já que os alunos desconheciam possibilidades mais complexas do uso de tal modalidade, também se assume a urgência de uma alteração metodológica e estrutural, no sentido de possibilitar a realização de atividades que efetivem um trabalho mais profundo e autêntico de ensino da língua. Isto é, no artigo, as autoras observam que o desafio de ensinar a língua em sua complexidade de uso passa fortemente por mudanças que devem implicar mais o aluno nos processos interativos da sala de aula. Mais que isso, afirmam ser possível e positiva essa abordagem, sobretudo quando consideram "o trabalho com a oralidade no que diz respeito à participação interativa do aluno dando voz a seus pensamentos ».

Já no artigo de Aline Fracarolli do Carmo, a estagiária foca sua análise a uma sequência de atividades que desenvolveu em torno do gênero quadrinhos, pautada, inicialmente pelo livro didático adotado pela escola. Um dos traços fundamentais da sua reflexão refere-se à necessidade de um trabalho docente que extrapole os limites do livro didático. Sendo assim, afirma: 
Buscar informações, atividades e conteúdos que possam complementar o que se tem no livro didático faz com que as aulas sejam mais dinâmicas, com maior participação do aluno, que muitas vezes prevê, antes mesmo de receber o comando da atividade registrada no livro didático, o que terá que fazer, pois propostas se repetem e são limitadas. (CARMO: 2017, p. 138)

Entretanto, resultado de um período de estágio marcado por limitações de toda ordem em função de uma situação estrutural precária do sistema escolar, tece as seguintes considerações:

Importante ressaltar que, com o atual sistema educacional, principalmente do estado do Paraná, no qual a hora-atividade do professor da rede estadual foi drasticamente reduzida, há professores que fazem jornadas triplas de trabalho para que possam obter a remuneração almejada ou suficiente, o que impossibilita um planejamento que possa contar com pesquisas em outros materiais. A falta de recursos também é um fator limitador de atividades diferenciadas por parte do professor, que se vê obrigado a pagar do próprio bolso materiais para seus alunos, até mesmo xerox de atividades que excedam a quantidade de direito de cada professor (que, ás vezes, não basta nem para as provas). Aparelhos de multimídia, como Datashow, não fazem parte da rotina do colégio em que foi realizado o estágio. Com isso, a tarefa de extrapolar o conteúdo do livro didático torna-se relativamente árdua. No entanto, devemos buscar meios de realizá-las com os recursos existentes, ainda que escassos. (CARMO: 2017, p.138-9)

Observa-se, no excerto acima, uma reunião bastante condensada dos aspectos apontados como frequentes nas reflexões oriundas dos registros dos DC. O aspecto relativo à auto-avaliação, nesse caso, parece colocar-se no sentido de manifestar o limite da crítica ao trabalho do professor da escola pública. Isto é, se antes a autora abordou a necessidade de extrapolação do livro didático, mostrando seu trabalho como exemplar dessa possibilidade, logo em seguida considera as dificuldades de tal proposição quando se ocupa efetivamente o lugar do professor submetido à precariedade estrutural diária. Desse modo, modaliza seu discurso, compreendendo os limites da ação docente em face da escassez de recursos, mas, ao mesmo tempo, não recua da noção de que é necessário persistir: "(...) a tarefa de extrapolar o conteúdo do livro didático torna-se relativamente árdua. No entanto, devemos buscar meios de realizá-las com os recursos existentes".

Subjaz, ainda, ao longo de todo o artigo, o reconhecimento dos desafios do ensino de língua portuguesa, quando faz referência aos limites do livro didático e à necessidade de introduzir outros materiais nas atividades de sala de aula. Nota-se, nesse sentido, a preocupação 
v. 8 (3)

$126-141$

out-dez

2018

em encontrar um aparato didático que corresponda às necessidades e desejos de aprendizagem dos alunos, conforme se observa no primeiro excerto, quando relata que o livro didático tornou-se repetitivo e previsível, pouco contribuindo para o desenvolvimento das práticas linguísticas dos alunos. Vale ressaltar que tais conclusões só têm condições de se efetivarem, dada a possibilidade de recuperação do contexto de observação e de regências, registrado no DC.

Por fim, não é exagerado afirmar que a percepção do contexto escolar enquanto espaço complexo de interação e produção de sentidos, nesse caso, se opera de modo bastante denso. A autora observa o ambiente de aprendizagem sendo constituído por uma gama vasta de informações e formações, as quais passam não só pela cena dialógica entre professor e alunos ou entre alunos e alunos. Todo o contexto de ensino, nesse caso, se constitui por uma polifonia em que se colocam as vozes dos alunos, dos professores, do estado - em seus silêncios, ausências e negações - da indústria cultural, todos se articulando e estabelecendo aquela ambiência de desenvolvimento da competência linguística.

Essa percepção, também favorecida pela possibilidade de rever as notas do DC e, assim, conceber uma imagem da situação da sala de aula contemporânea, certamente conduz a um perfil docente marcado por um olhar complexo a respeito do seu fazer, ciente de que sua ação e a de seu aluno não podem ser tomadas como fatos isolados, sendo necessário, portanto, recriar-se e reestruturar-se a todo momento, num processo de formação constante.

\section{Considerações finais}

Neste artigo, procurou-se apresentar a relevância do estágio supervisionado enquanto instância formativa, devido à possibilidade de articulação entre elementos teóricos e práticos.

Para tanto, intentou-se defender as metodologias ativas como caminho mais adequado na formação de uma identidade docente cujo perfil corrobore com o conceito de professor-pesquisador.

Buscando efetivar um trabalho de supervisão que possibilite a formação da identidade docente pautada pela autonomia e criticidade, sugeriu-se o diário de campo (DC) como ferramenta privilegiada na consecução de reflexões e sistematizações oriundas do diálogo constante entre teoria e prática, conforme preveem as metodologias ativas. 
Relatou-se o processo de trabalho com o DC nos anos de 20162017, mostrando como alunos do $3^{\circ}$ ano do curso de Letras apropriaramse criticamente das suas observações e práticas, constituindo o princípio de uma identidade docente fundamentada na autonomia e na ética.

Nos excertos analisados, observam-se não só a apropriação do espaço da docência em termos metodológicos e estratégicos, mas, sobretudo, no plano ético, isto é, no modo como as autoras se posicionam em relação à escola, ao ensino e à relevância do conhecimento letrado numa sociedade de, ainda, tão restritos acessos.

\section{Referências}

BERBEL, Neusi Aparecida Navas. As metodologias ativas e a produção da autonomia dos estudantes. Semina: Ciências Sociais e Humanas. Londrina, v. 32, n. 1, p. 25-40, jan./jun. 2011.

CARMO, Aline Fracarolli do. Práticas didáticas e uma experiência de estágio no ensino fundamental 2. In: Estagiar: Encontro do Estágio de Língua Portuguesa e Literaturas de Língua Portuguesa, 1., Londrina. Anais... Universidade Estadual de Londrina, v. 1, n.1, 2017, p. 132-139.

FAGUNDES, Tatiana Bezerra. Os conceitos de professor pesquisador e professor reflexivo: perspectivas do trabalho docente. Revista Brasileira de Educação. Rio de Janeiro, v. 21, n. 65, p. 281-298, abr./jun. 2016.

GALVÃO, Patrícia Medeiros da Silva; SÁ, Natália Cristina Martins de. Leitura, produção de texto e análise linguística no ensino fundamental 2: relatos de práticas de estágio. In: Estagiar: Encontro do Estágio de Língua Portuguesa e Literaturas de Lingua Portuguesa, 1., Londrina. Anais... Universidade Estadual de Londrina, v. 1, n.1, 2017, p.100-110.

GERALDI, João Wanderlei. Portos de passagem. São Paulo: Martins Fontes, 1997.

RANCIERE, Jacques. Uma aventura intelectual. In: RANCIERE, J. o mestre ignorante: cinco lições sobre a emancipação intelectual. Tradução de Lilian do Vale. Belo Horizonte: Autêntica, 2013.

ROESE, Adriana; GERHARDT, Tatiana Engel; SOUZA, Aline Corrêa de; LOPES, Marta Jullia Marques. Diário de campo: construção e utilização em pesquisas científicas. Online Brazilian Journal of Nursing, Porto Alegre, v. 5, n. 3, 2006. (Disponível em http://www.objnursing.uff.br/ index.php/nursing/article/view/598/141 - último acesso 29/05/18)

SILVA, Tomaz Tadeu. A produção social da identidade e da diferença. In: SILVA, T.T. (org.) Identidade e diferença: a perspectiva dos estudos culturais. Petrópolis: Vozes, 2012, p. 73-102. 